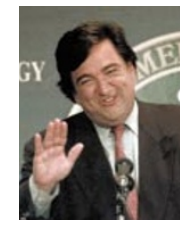

Fond farewell

Outgoing energy minister bolsters morale at US labs p548

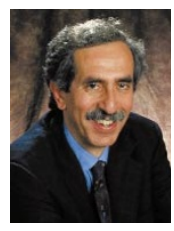

Healthy future

Canada sets its sights high for medical research p549

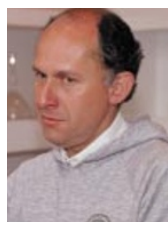

Bank statement Colombian institute paralysed by debt collectors p550

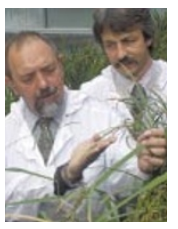

\title{
Hughes institute will put down roots to develop research tools
}

Colin Macilwain, Washington

In a radical change of direction, the Howard Hughes Medical Institute (HHMI) will this week announce plans to build a \$500 million research campus near Washington DC.

The creation of a permanent research base is a new move for Hughes, the largest medical research charity in the United States. Until now, it has concentrated on supporting an élite of individual investigators based at US universities.

The campus will be built on a green-field site near Washington Dulles Airport in northern Virginia. HHMI officials envisage that collaborations there between biologists, chemists, physicists and engineers will specialize in developing new research tools. "It is at the interface between the disciplines that the sparks are going to fly," says Tom Cech, HHMI's president. The campus is expected to open its doors by 2005.

The Howard Hughes Investigator programme - which supports 348 researchers to the tune of around $\$ 1$ million a year each - has worked well, most observers say. Its researchers include many of the

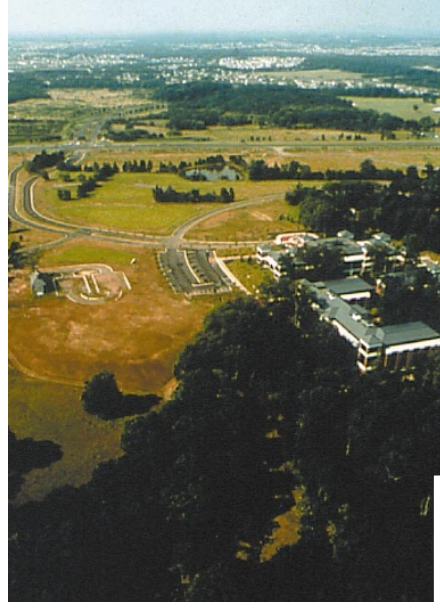

Watch this space: Cech (right) wants to keep the new campus 'fresh'.

United States' most eminent life scientists. And the absence of any permanent research infrastructure has shielded Hughes from criticisms of empirebuilding or from any sense of stagnation.

But Hughes needs to expand - it is required by law to spend $3.5 \%$ of its fastgrowing endowment on medical research each year. And biomedical researchers' growing appetite for sophisticated and expensive research tools has convinced HHMI officials that there is an opportunity for a vibrant new centre specializing in the development and use of such tools.

"Ramping up the number of principal investigators [to 348] was the right strategy for the 1990s," says Cech. "But biology is now switching over, to benefit from bigger installations."

HHMI officials mention Pat Brown, a Hughes investigator and geneticist at Stanford University, as the sort of researcher who might be induced to join the new establishment. Brown has pioneered the development of microarray techniques in genetics. David Clayton, the vice-president for scientific development at HHMI, says it will attract "people who really enjoy bringing state-ofthe-art technology to bear" on scientific problems.

As well as working on research tools, the

\section{Ethics watchdog to oversee drugs trials in Third World}

Matthew Davis, Washington

Tighter controls for US-funded medical research involving human subjects in the developing world were announced last week by the US Department of Health and Human Services.

In response to growing concerns from both the press and scientific advisory groups - over ethical standards for clinical trials in developing countries, the department has set up an Office of International Activities.

The new division, to be located within the Office for Human Research Protections (OHRP), will oversee, but not regulate, federally funded trials in developing countries and provide ethical guidance.

The OHRP already regulates federally funded scientists working abroad, although research by drug companies is controlled by the Food and Drug Administration.

A recent series of articles in The

Washington Post, criticizing the way US researchers operate in developing countries, depicted large pharmaceutical companies and some federally funded researchers - as increasingly exploiting vulnerable patient populations in poor countries.

For example, Pfizer was criticized for a 1996 clinical trial in Nigeria, in which its antibiotic trovafloxacin was tested on children and infants with meningitis. The Washington Post portrayed the company as taking advantage of a meningitis epidemic, but Pfizer rejected the charges, saying that the trial played "an important role in investigating a potential breakthrough in oral therapy for this terrible epidemic".

The Washington Post articles have prompted calls for a congressional health panel to seek hearings on the issue, and “a legislative response".

The issue is also being driven by the National Bioethics Advisory Commission and the World Medical Association, which had intensified their involvement before the newspaper series began.

The organizations were spurred into action partly by complaints that began three years ago over a Ugandan clinical trial in which HIV-positive pregnant women were given placebos even though, critics claimed, a proven therapy was available that could have saved the unborn child from infection.

The two organizations advise scientists not to use placebos in developing countries when effective treatments exist. But critics argue that without a placebo group it is often impossible to gauge the effectiveness of a new therapy. 
campus will serve as what Gerry Rubin, Hughes vice-president for research, calls a "research hotel", where teams of visiting scholars, who may or may not be Hughes investigators, can spend time together working on projects of interest. The groups could come "for a few months, or even a couple of years", says Rubin. "No university can hold space open for that."

The facility will be built on a recently acquired 281-acre site. It will house around 24 principal investigators and up to 300 support staff, plus visiting scientists. Hughes has put aside $\$ 500$ million for the project over 10 years, including planning, construction and $\$ 50$ million a year for operations after 2005. A director will be appointed about a year before operations begin.

Hughes officials say that investigators at the campus will not have tenure, although their five-year appointments will be renewable. "We've spent a lot of time discussing how to keep it fresh," says Cech. "We think we can keep people moving in and out of the place."

Cech and Rubin arrived at HHMI at the start of 2000 (see Nature 402, $334-335$; 1999) and have since been working on a new direction for the charity. The announcement is its central component. "This is something that the new leadership group here has cooked up," says Cech.

\section{Weapons labs escape FBI action}

\section{Irwin Goodwin, Washington}

Bill Richardson, the US energy secretary in Bill Clinton's administration, spent his last two days in office trying to restore the morale and motivation of thousands of scientists at US nuclear weapons labs.

He announced that, after a seven-month investigation, the FBI will not be bringing criminal charges against any workers at the Los Alamos National Laboratory (LANL) in New Mexico, where two computer hard drives containing secret nuclear-weapons data temporarily went missing last spring.

The FBI "was unable to determine responsibility for the disappearance ... and found no evidence that the classified information contained on the hard drives had been compromised", the energy department said in a statement.

At least four Los Alamos employees had been investigated in connection with the disappearance. Coming close on the heels of the high-profile Wen Ho Lee affair - in which a Taiwan-born computer scientist working at LANL had been accused of passing classified information to China the investigation had seriously shaken the morale of the laboratory's scientists.

Richardson also extended the energy department's contract with the University of California to manage LANL and its sister

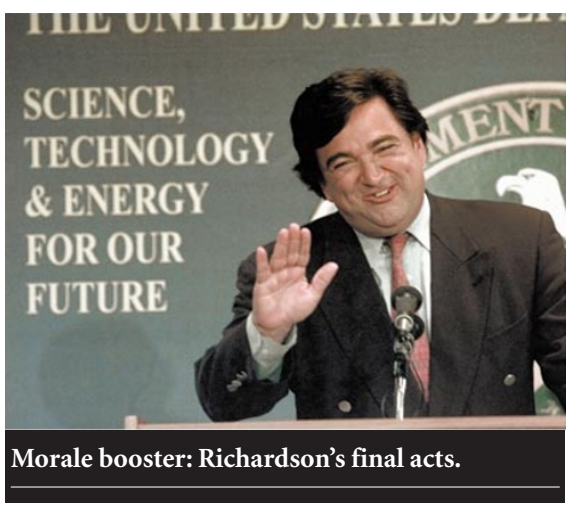

Lawrence Livermore laboratory near San Francisco until September 2005. The university has always managed the weapons labs, but had recently been criticized by Congress and the energy department for allowing apparent security lapses.

In addition, Richardson withdrew the threat of polygraph tests for workers, which he had announced after Wen Ho Lee was sacked nearly two years ago. Initially he wanted 8,000 employees, mostly scientists, to take the test, but reduced this to 400 after many resigned and young researchers refused to accept jobs. "We have great scientists in the weapons labs," Richardson says, "and we have to make sure we can retain and recruit the best and brightest."

\section{Journal will publish accused scientist's work}

\section{Rex Dalton, San Diego}

After months of debate, a leading journal has decided it will consider for publication the research by a renowned geochemist accused of criminal offences unconnected to his work

Geochimica et Cosmochimica Acta has been in turmoil for months after two articles were submitted co-authored by Yale University professor Antonio Lasaga, who has been charged with child sex crimes. Lasaga specializes in the kinetics of geochemical processes.

The Reed Elsevier journal is jointly sponsored by the Geochemical Society and the Meteoritical Society. The journal's editor, Frank Podosek, a professor at Washington University in St Louis, Missouri, decided not to publish research bearing Lasaga's name, saying he wanted to protect the societies and the journal. "I didn't want to create the impression we were looking the other way," Podosek says.

Two other co-authors on the articles Hiroshi Ohmoto of Pennsylvania State University and Andreas Luttge of Rice University in Texas - immediately filed complaints with the journal's publications committee.

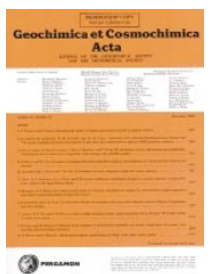

Luttge, an associate professor now seeking tenure at Rice after studying under a German fellowship with Lasaga at Yale, is upset by the publication delay. "I have to feed my family," says Luttge, "and proceed with my career. I spent four years at Yale - I can't throw out that work."

Lasaga and his attorneys declined interview requests. Lasaga has pleaded guilty to two federal felonies for possession of child pornography, but has since attempted to withdraw the pleas. He also faces state charges for alleged sexual abuse of a young boy. $\mathrm{He}$ has pleaded innocent in this case.

As tensions mounted in the geochemical societies over whether to publish the papers, Podosek polled the journal's 55 associate editors on their positions. About two-thirds of those responding supported publication of Lasaga's work, says Podosek. But Podosek stood firm in his view.

A compromise was finally worked out by Geochemical Society president Michael Hochella of Virginia Polytechnical Institute, and the University of Arizona's Michael Drake, the former president of the Meteoritical Society.

Under the arrangement, Podosek will not handle research articles where Lasaga is an author - an associate editor will direct them through the normal peer-review process.

"This has been an extraordinarily difficult situation for all concerned," say Hochella and Drake in a joint statement. "Our societies do not have a mechanism to deal with reviewing papers based on anything other than scientific merit and the standard ethical aspects of scientific research."

At their annual meetings later this year, the societies' boards will consider adopting a policy to "define such a mechanism", the statement says. Meanwhile, Podosek and Lasaga's co-authors were satisfied with the outcome. "They made the right decision," says Ohmoto.

But others were more critical. Nicholas Cozzarelli, a molecular biologist at the University of California and editor of the Proceedings of the National Academy of Sciences, says: "The [Lasaga] papers should be treated like any others. It is a slippery slope when editors make decisions on non-scientific matters." 